\title{
Retrospective Descriptive Analysis of a University Undergraduate Community Medicine Question Papers, Karnataka
}

\author{
${ }^{1}$ Kruthika Nagaraj, ${ }^{2}$ Renuka Prithviraj, ${ }^{3}$ Rajappa Maheswaran
}

\begin{abstract}
Introduction: Summative assessment of students is done to know whether the student is competent enough for certification. As all assessment methods have some intrinsic flaws, solutions need to be identified to reduce these flaws before implementation.

Aim: To evaluate the validity of content in the university undergraduate community medicine question papers and suggest a blueprint format to be used in designing community medicine question paper.

Materials and methods: It is a retrospective descriptive analysis. Undergraduate community medicine theory question papers (papers I and II) of the last nine years, from 2008 to 2016, of a selected university in Karnataka were analyzed for content coverage, weightage, etc. Data are expressed as frequency, percentages, median, and interquartile range.
\end{abstract}

Results: Analysis of the question papers revealed that in majority of the papers, there was good coverage of all the chapters. Majority (57.6\%) of the questions assessed knowledge followed by comprehension (33.1\%), application skills (9\%), and only $0.3 \%$ questions assessed analysis skills. Majority of the marks were from questions of must-know topics.

Conclusion: The present study establishes the scope for improvement while designing question papers in community medicine examinations. Also, blueprint should be an integral part of assessment.

Keywords: Blueprint, Community medicine, Evaluation, Undergraduates, Validity.

How to cite this article: Nagaraj K, Prithviraj R, Maheswaran R. Retrospective Descriptive Analysis of a University Undergraduate Community Medicine Question Papers, Karnataka. J Postgrad Med Edu Res 2018;52(3):105-109.

Source of support: Nil

Conflict of interest: None

\section{INTRODUCTION}

Medical education and health care in India are facing serious challenges in content and competencies. ${ }^{1}$

\footnotetext{
${ }^{1}$ Assistant Professor, ${ }^{2,3}$ Professor

${ }^{1-3}$ Department of Community Medicine, Sapthagiri Institute of Medical Sciences and Research Centre, Bengaluru, Karnataka India

Corresponding Author: Kruthika Nagaraj, Assistant Professor Department of Community Medicine, Sapthagiri Institute of Medical Sciences and Research Centre, Bengaluru, Karnataka, India e-mail: kruthika.gowda1@gmail.com
}

Evaluation of any activity is an ongoing process and in the wake of the Medical Council of India's call to restructure the curriculum, the need arises to look into the gaps in the assessment process also. Assessment is a key method for measuring the extent to which the goals of any curriculum have been established and thus, the assessment procedure should be carefully designed and conducted.

Written examination using question paper is still a widely used tool of both formative and summative evaluation which cannot be replaced entirely by any other method. ${ }^{2}$ Four attributes of assessment are validity, reliability, acceptability, and consequences. ${ }^{3}$ A theory question paper as a tool of assessment should have good content coverage, and proper weightage to each content, proper weightage to different learning objectives, appropriate difficulty level of questions based on Blooms taxonomy and a well-designed marking scheme. ${ }^{4}$ To facilitate more outcome-focused education objectives, the original levels by Bloom et al have been revised by Anderson and Krathwohl. ${ }^{5}$ The present study was conducted with the objectives to evaluate the validity of content in the university undergraduate community medicine question papers of the last 9 years and suggest a blueprint format to be used in designing community medicine question paper.

\section{MATERIALS AND METHODS}

A retrospective descriptive study of the Bachelor of Medicine, Bachelor of Surgery phase III part 1, Community Medicine university-level theory question papers (papers I and II) retrospectively for the last nine years from 2008 to 2016 was done. Summative evaluation of students for Community Medicine is done at the end of 3rd year. The University conducts exams during May / June and December/January of every year for different batches. In Community Medicine, students are assessed in the theory examination through two question papers of 100 marks each, and paperwise topic division has been specified in the curriculum. The component of each question paper is as follows: two long essays (10 marks each), ten short essays ( 5 marks each), and ten short answer type of questions (3 marks each), all totaling 100 marks to be answered in a three-hour duration. 
Table 1: Distribution of chapterwise marks in papers of last 9 years and hours allotted as per syllabus

\begin{tabular}{llll}
\hline Chapter & Hours allocated & Median (IQR) marks & Min-Max marks \\
\hline Man and medicine, concept of health and disease & 17 & $13(5.5-21)$ & $0-28$ \\
Environment and health & 17 & $16(10.5-23.5)$ & $3-31$ \\
Sociology & 14 & $3(0-5)$ & $0-11$ \\
Health education & 5 & $5(3-8)$ & $0-15$ \\
Mental health & 1 & $3(0-5)$ & $0-6$ \\
Genetics & 2 & $(0-4)$ & $0-11$ \\
Occupational health & 8 & $8(5-15)$ & $0-18$ \\
Health information and statistics & 16 & $8(4-11)$ & $0-18$ \\
Epidemiology & 19 & $26(18-36.5)$ & $11-43$ \\
Nutrition & 10 & $16(11.5-19.5)$ & $0-23$ \\
Demography & 10 & $3(0-6.5)$ & $0-11$ \\
Communicable diseases & 27 & $31(19-44.5)$ & $3-52$ \\
Noncommunicable diseases & 13 & $13(8-20)$ & $3-29$ \\
Health systems/urban health & 8 & $10(1.5-13)$ & $0-29$ \\
Planning and management & 5 & $3(0-6.5)$ & $0-13$ \\
Health programs in India & 13 & $5(4-10)$ & $0-26$ \\
Reproductive and child health & 17 & $21(12-28.5)$ & $3-50$ \\
School health & 1 & $(0-3)$ & $0-8$ \\
International health & 2 & $5(0-5)$ & $0-8$ \\
Geriatrics & 1 & $(0-4)$ & $0-10$ \\
Disaster management & 2 & $3(0-3)$ & $0-5$
\end{tabular}

IQR: Interquartile range

All the available papers were assessed for content coverage and weightage given to each content. Also, the level of cognitive domain (based on verbs used to write behavioral objectives, according to revised Bloom's criteria), suitability to fit into must know/desirable to know criteria (as per university curriculum) and proportion of marks allotted topic wise in both the papers was noted. To calculate content weightage, number of hours was allocated to different chapters arbitrarily, matching the total term wise hours prescribed in the university curriculum (Table 1). Of the 17 sets of question papers with 44 questions in each set (22 questions each in papers I and II), a total 748 questions were analyzed. Approval has been obtained from the institutional ethical committee.

\section{Statistical Analysis}

The data were compiled into Microsoft Excel worksheet. Data were analyzed using Statistical Package for the Social Sciences version 20. Data are expressed in terms of frequency, percentages, median, and interquartile range. The data are also presented in the form of tables and graphs.

\section{RESULTS}

The validity assessment of past 9 years' question papers with respect to content coverage, weightage given to each content, and difficulty level of questions revealed as follows: Content coverage: analysis of the question papers revealed that in the majority of papers, there was good coverage of all the chapters, except in a few papers wherein questions from certain chapters were not covered (Graphs 1 and 2).

Weightage given to content: As seen from Graphs 1 and 2 , there was no uniformity in weightage given to different chapters in the papers across different years. Few chapters like Epidemiology, Environment and health, Nutrition, Communicable diseases and Reproductive and Child Health were given more emphasis. Questions from certain chapters like communicable diseases accounted to more than 40 marks per 100 mark paper in six papers to as low as three marks during a year. Questions of must know topics ranged from 87.5 to $98.5 \%$ of the marks, while 1.5 to $12.5 \%$ of marks was from questions of desirable to know category. Table 1 describes the median marks of different chapters across the question papers of different years in relation to the hours allocated to those chapters as per university curriculum.

Difficulty level of questions according to revised Bloom's criteria: In the present study, out of 748 questions in all the papers, about 431 (57.6\%) questions assessed knowledge (Bloom 1), followed by 248 (33.1\%) questions assessed comprehension (Bloom 2), 67 (9\%) assessed application skills (Bloom 3), and only 2 (0.3\%) questions assessed analysis skills (Bloom 4). As seen in Graph 3, questions assessing knowledge ranged from 34 to $79.5 \%$, those assessing comprehension ranged from 16 to $52.3 \%$, and questions assessing analyzing skills were noted only in papers during 2 years. Overall, more weightage was given to questions assessing knowledge and comprehension. There was no 


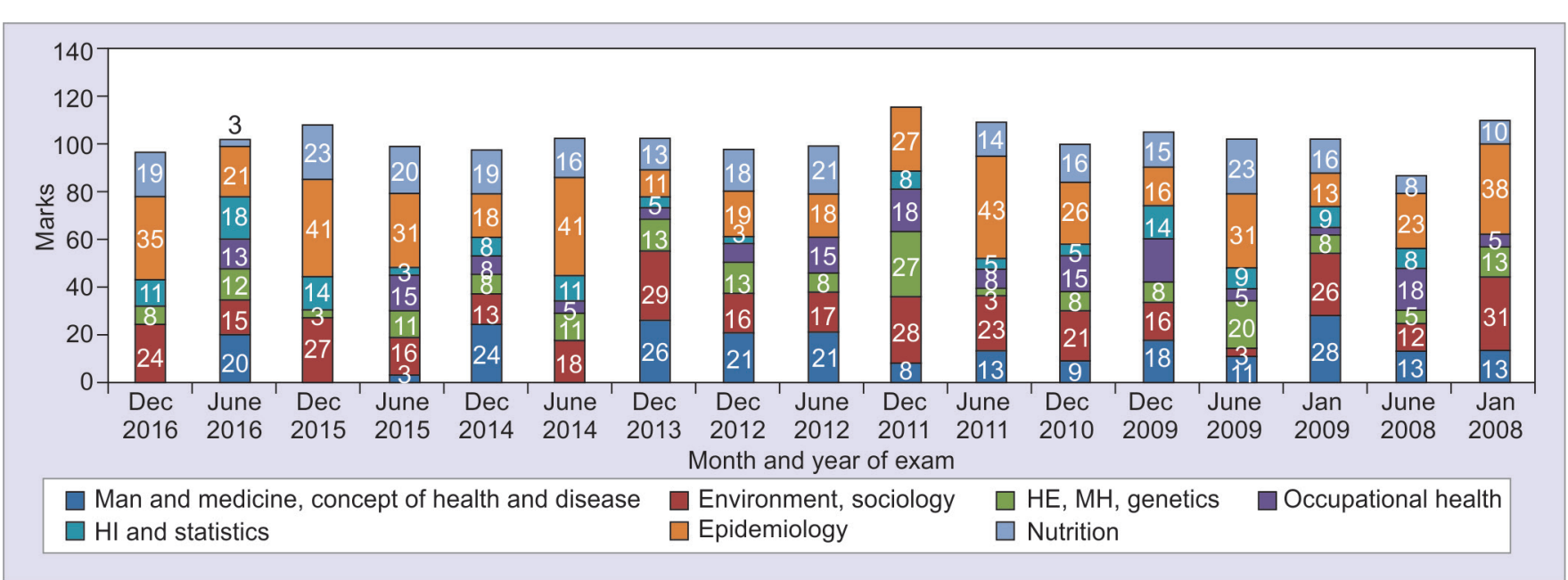

Graph 1: Distribution of marks of paper I topics during different years. HI: Health information; HE: Health education; $M H$ : Mental health. The total marks cross 100 in few bars as questions from paper I topics were asked in paper II also

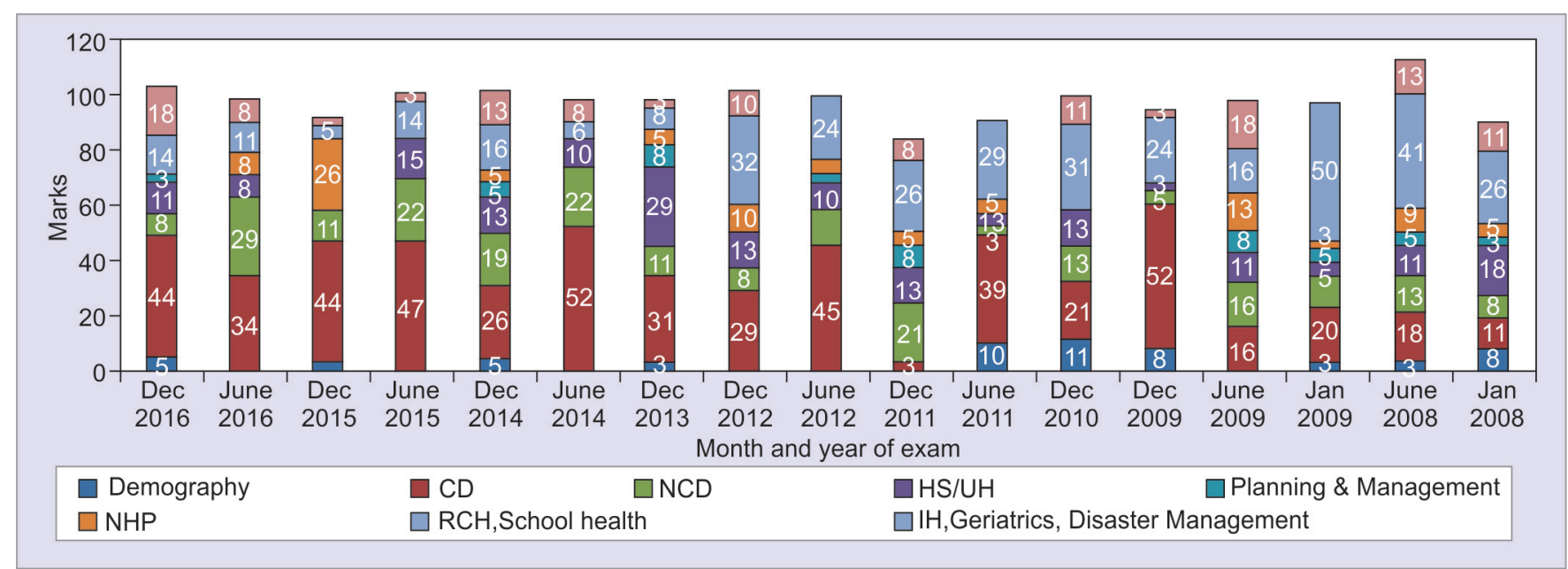

Graph 2: Distribution of marks of paper II topics during different years. CD: Communicable diseases; NCD: Noncommunicable diseases; HS: Health systems; UH: Urban health; NHP: National health programs; RCH: Reproductive and child health; IH: International health; The total marks cross 100 in few bars as questions from paper II topics were asked in paper I also

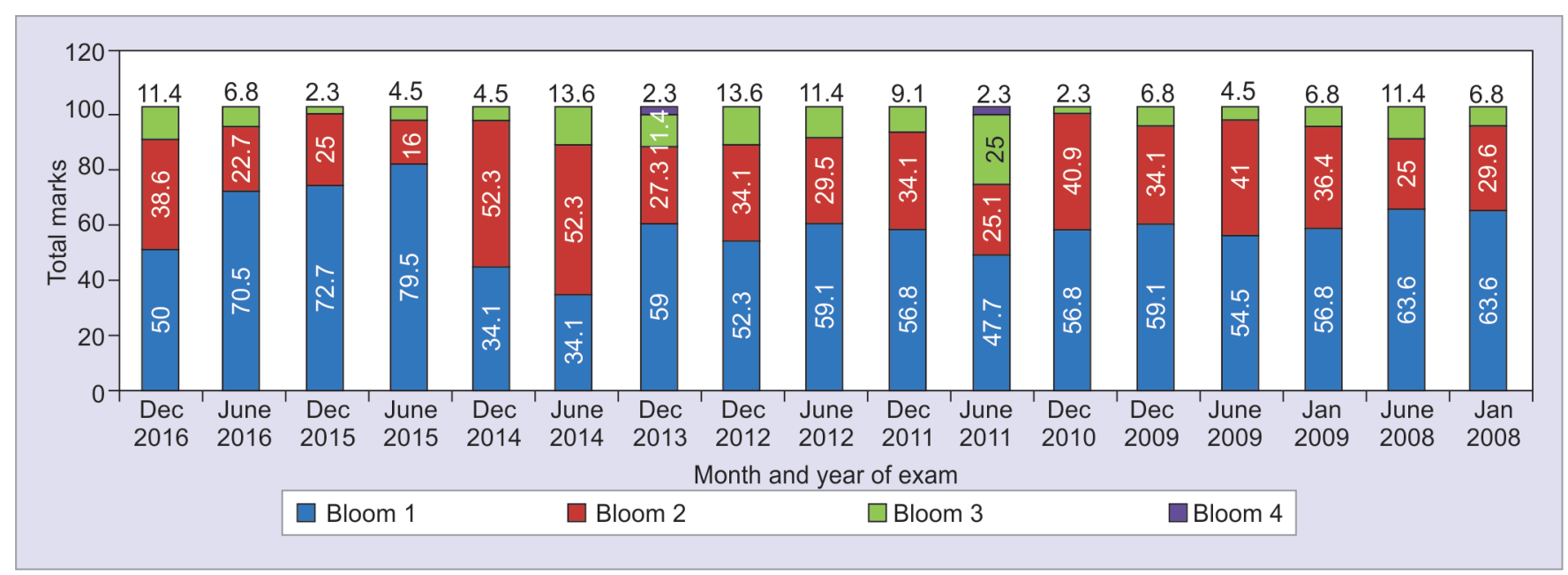

Graph 3: Distribution of marks in papers according to levels of cognitive domain 
division of marks specified to the subquestions of the long essay. Majority of the questions were precise as to what examiner wants, while a few short essays and short answer type questions did not have any verbs being used like lead poisoning, pneumoconiosis, Community Health Centre, etc., which lead to lack of precision of questions as it does not indicate what the examiner wants. It was observed that the language used in the question papers was clear and unambiguous.

\section{DISCUSSION}

Students focus on learning what is asked in the examinations. Teachers can exploit this potential of assessment to give a particular direction to student learning. Assessment in medical education is important as students will be certified as fit to deal with human lives. ${ }^{3}$ Our analysis revealed that majority of the question papers had good content coverage, but there was no uniformity in coverage of entire curriculum. Also, weightage for contents was not uniform through the papers of different years. The assessment tool was targeted mainly toward testing the remembering and understanding abilities, which form the lower order of cognitive domain, while the difficulty level of questions assessing applying and analyzing skills were rarely asked. Assessment of most complex levels like evaluating and creating was lacking. There could be mention of distribution of marks to the subquestions / different sections in the long essay, which would facilitate better marking scheme with objectivity in allotting marks. Precision could be improved by using verbs in framing questions indicating what the examiner expects of the question.

Similar studies on Community Medicine question papers from other universities were not available for comparison. Evaluation of undergraduate Medical Physiology question papers of the same university revealed that the cumulative examination questions on an average focused more on comprehension (28\%), followed by knowledge (14\%), application (6\%), analysis (5\%), synthesis ( $2 \%)$, and none on evaluation, and $45 \%$ of the questions had no usage of any verbs. ${ }^{6}$ Analysis of Microbiology question papers for cognitive domains showed $8 \%$ of the questions tested factual recall, $10 \%$ tested data interpretation, and 15\% questions tested critical evaluation, and $67 \%$ question did not belong to any of the cognitive domains. ${ }^{7}$

Having a blueprint of question paper for individual subjects would help maintain the uniformity in setting the papers. The effective use of a blueprint would have resolved the above situation. Blueprint is a specification that ensures that all aspects of the curriculum and educational domains are covered by assessment programs over a specified period of time. ${ }^{8}$ As validity is a requirement of every assessment and to bring in consonance between learning objectives and assessment, an attempt was made to design a blueprint for the theory question paper covering the entire subject of community medicine.

The presence of a blueprint will also enable students to direct their learning efforts. ${ }^{9}$ It will also reduce the two major threats to validity, construct underrepresentation and construct irrelevance variance. ${ }^{10}$ To prepare a blueprint, weightage to be given to different topics and the proportion of marks allocated to assess different domains of learning has to be estimated. Two parameters generally considered while calculating weightage are (i) the perceived impact/importance of a topic in terms of its impact on health and (ii) the frequency of the occurrence of a particular disease or health problem. ${ }^{9}$ However, these parameters appear to have subjectivity and for a subject like community medicine where topics like national health programs, planning and management, and health care delivery are to be taught, there is difficulty in application of the above parameters. Studies have been published with samples of blueprint made by taking factors like frequency of occurrence of questions in university papers and public health importance of a problem.

Here, an attempt has been made to prepare a blueprint using the number of teaching hours allotted termwise for a group of chapters as per university guidelines. The teaching hour for every chapter was then framed arbitrarily. The proportion of marks allocated for every chapter can be calculated based on the corresponding proportional teaching hours the chapter has contributed. For example, if total marks is 200 and the hours contributed by chapter I is 5 out of 100 hours, proportion of hours contribute by the chapter $\mathrm{I}=0.05(5 \%)$. The same proportion can be used to calculate the marks to be allotted, i.e., $0.05 \times 200=10$.

For the domains, as the higher level of Bloom's are considered to closely approximate professional reality, the proportion of marks for different levels of Bloom's was arbitrarily allocated as shown in Table 2 . The column on learning objectives will ensure completeness of curriculum.

\section{CONCLUSION}

The present study establishes the need of improving the quality of community medicine question paper in examinations with emphasis on assessing higher levels of cognitive domains among the undergraduates. Use of blueprint would facilitate preparing question papers with good content coverage and proper weightage distribution, and it also acts as a valid tool to frame the assessment in line with the curricular objectives. 


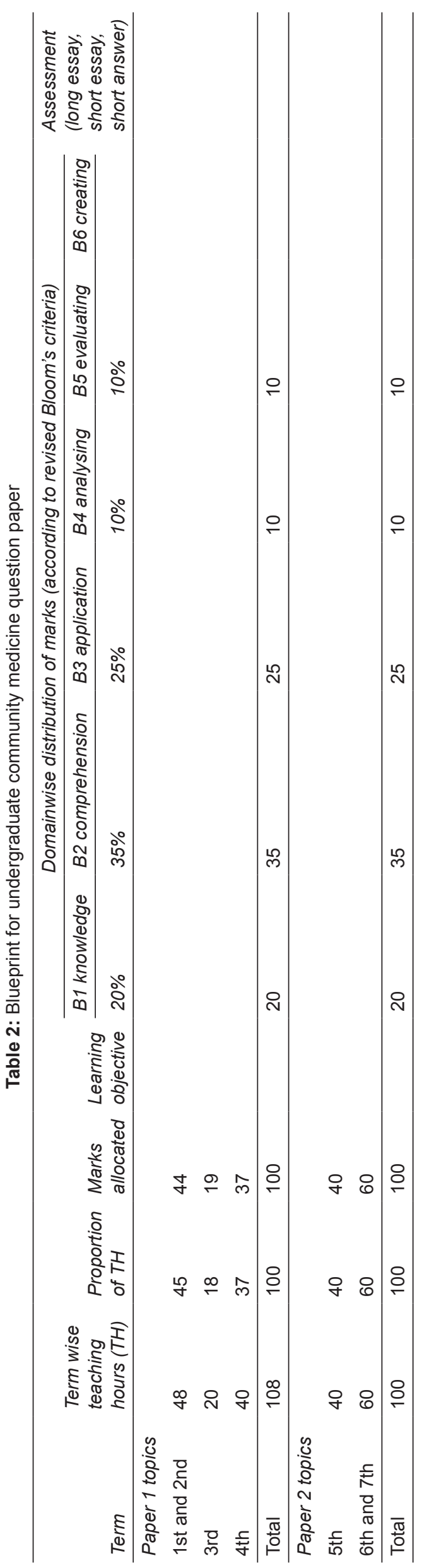

\section{ACKNOWLEDGMENT}

Authors would like to thank sincerely the Rajiv Gandhi University of Health Sciences, Karnataka.

\section{REFERENCES}

1. Medical Council of India. Vision 2015. New Delhi: MCI; 2011. [cited 2016 Sep 13]. p. 9. Available from: https:/ / old.mciindia. org/tools/announcement/MCI_booklet.pdf.

2. Ananthkrishnan, N.; Sethuraman, KR.; Santosh, K. Medical education-principles and practice. 2nd ed. Puducherry: Alumni Association of National Teacher Training Centre; 2000.

3. Singh, T. Basics of assessment. In: Singh T, Anshu, editors. Principles of assessment in medical education. New Delhi: Jaypee Brothers Medical Publishers; 2012. pp. 1-13.

4. Kumar A, Patel S. An analytical study of mathematics question papers of Madhya Pradesh board with respect to its patterns/design, content coverage, difficulty level, objectivity in marking and its impact on achievement of students. IJAESS 2014;2(2):16-23.

5. Huitt, W. Bloom et al.'s taxonomy of the cognitive domain. Educational psychology interactive. Valdosta (GA): Valdosta State University. 2011. [cited 2016 Sep 13]. Available from: http://www.edpsycinteractive.org/topics/cognition/bloom. pdf.

6. Kalasuramath S, Tandon M, Deshpande DV, Kumar V. Application of blooms taxonomy of verbs to evaluate the cognitive domain in undergraduate medical physiology question papers: a critique. Int J Res Med Sci 2015 Nov;3(11): 3351-3356.

7. VinodKumar CS, Suneeta K, Lakshmi RP, Jayasimha VL, Basavarajappa KG, Niranjan GV. Descriptive analysis of the MBBS Microbiology Question Papers of RGUHS, Bengaluru. J Educ Res Med Teach 2014;2(1):29-32.

8. Adkoli, B. Attributes of a good question paper. In: Sood R, editor. Assessment in medical education: trends and tools. New Delhi: KL Wig Center for Medical Education and Technology, AIIMS; 1995.

9. Adkoli, B.; Deepak, KK. Blue printing in assessment. In. Singh T, Anshu, editors. Principles of assessment in medical education. New Delhi: Jaypee Publishers; 2012. pp. 205-213.

10. Patil SY, Hashilkar NK, Hungund BR. Blueprinting in assessment: how much is imprinted in our practice? J Educ Res Med Teach 2014;2(1):4-6. 